\title{
Comparative patterns of follicle development and selection in ruminants
}

\author{
G. P. Adams \\ Veterinary Anatomy, Western College of Veterinary Medicine, University of Saskatchewan, \\ Saskatoon, Saskatchewan, S7N 5B4, Canada
}

Expanding technological capabilities, particularly in ultrasonography and molecular endocrinology, have bridged the gap between form and function of the ovary, and have been a catalyst for intense research activity in this area during the last decade. However, the study of follicular dynamics is still in its infancy in ruminant species other than cattle, and controversy persists regarding the pattern of follicular growth and the existence of follicular dominance. The bovine model of ovarian function is presented as a foundation for concepts surrounding the control of follicular development in ruminants, and to place in context the results of recent studies in sheep, goats, muskoxen, cervids and camelids. This comparative approach is used to determine important generalities that appear to be applicable, as fundamental physiological phenomena, to all ruminant species. Although clear differences in follicular dynamics are evident, differences appear to be specific rather than general, and the following conclusions are consistent with results reported in ruminant species to date: (1) follicles grow in a wave-like fashion; (2) periodic surges in circulating FSH are associated with follicular wave emergence; (3) selection of a dominant follicle involves a decline in FSH and acquisition of LH responsiveness; (4) periodic anovulatory follicular waves continue to emerge until occurrence of an LH surge (that is, at the time of luteolysis during the ovulatory season or during transition from the anovulatory season); (5) within species, there is a positive relationship between the duration of the oestrous cycle and the number of follicular waves; (6) progesterone suppresses LH secretion and growth of the dominant follicle; (7) the duration of the interwave interval is a function of follicular dominance, and is negatively correlated with circulating FSH; (8) follicular dominance in all species is more pronounced during the first and last follicular waves of the oestrous cycle; and (9) pregnancy, the prepubertal period and seasonal anoestrus are characterized by regular, periodic surges in FSH and emergence of anovulatory follicular waves,

\section{Introduction}

The kinetics of follicular development are best characterized in cattle. The bovine model is presented first to introduce the concept of follicular wave dynamics and the fundamental mechanisms involved. Historically, there has been a lack of scientific consensus regarding the pattern of ovarian follicular development within and among species. However, results of recent studies, using a number of different methods, are increasingly consistent and it appears that the wave phenomenon is common to cattle of different breeds, to several domestic and wild ruminant species, and to different reproductive and lactational states. The intent of this review is to provide a comparative overview of ovarian follicular development in ruminants. 


\section{Bovine Model of Ovarian Function}

\section{Follicular dynamics during the oestrous cycle}

Greater than $95 \%$ of oestrous cycles are composed of either two or three follicular waves (Fig. 1; Ginther et al., 1989a; Savio et al., 1988; Sirois and Fortune, 1988; Adams, 1994). Single-wave cycles have been reported in heifers at the time of puberty (Evans et al., 1994a) and in mature cows during the first interovulatory interval after calving (Murphy et al, 1990; Savio et al., 1990). Four-wave cycles are observed occasionally in Bos indicus (Rhodes et al., 1995; Zeitoun et al., 1996), but most oestrous cycles composed of four or more follicular waves are accompanied by a prolonged interovulatory interval as a result of delayed luteolysis or failure to ovulate (Adams et al., 1992a; Roche and Boland, 1991). The proportion of animals with two- versus three-wave cycles differs between studies; some report a majority of two-wave cycles (> 80\%, Ginther et al., 1989a; Rajamahendran and Taylor; 1990; Ahmad et al., 1997) and others report a majority of three-wave cycles (>80\%, Sirois and Fortune 1988), while others have observed a more even distribution (Evans et al, 1994a; Savio et al., 1990). Although the subject has not been studied extensively, there appears to be no clear breed- or agespecific preference for a particular follicular wave pattern, and no difference in pregnancy rate was detected between two- and three-wave animals (Ahmad et al., 1997). In a study of the effects of nutrition on follicular dynamics (Murphy et al., 1991), cattle fed a low energy ration had a greater proportion of three-wave cycles than those fed higher energy rations. Whether the pattern (that is, either two-wave or three-wave) within individuals is reproducible has not been investigated. The evolutionary reason for a two- or a three-wave cycle, or indeed for the wave-like pattern itself, is unclear, but differences between wave patterns are distinct and have important implications regarding schemes for ovarian synchronization and superstimulation (Adams, 1994).

The wave pattern of follicular development refers to periodic, synchronous growth of a group of antral follicles. In cattle, follicular wave emergence is characterized by the sudden (within 2-3 days) growth of 8-41 (average $=24$ ) small follicles that are initially detected by ultrasonography at a diameter of 3-4 mm (Pierson and Ginther, 1987a; Savio et al., 1988; Sirois and Fortune, 1988; Ginther et al., 1989a, 1996b). For about 2 days, growth rate is similar among follicles of the wave, then one follicle is selected to continue growth (dominant follicle) while the remainder become atretic and regress (subordinate follicles). In both two- and three-wave oestrous cycles, emergence of the first follicular wave occurs consistently on the day of ovulation (day 0). Emergence of the second wave occurs on day 9 or 10 for two-wave cycles, and on day 8 or 9 for three-wave cycles. In three-wave cycles, a third wave emerges on day 15 or 16 . Under the influence of progesterone (for example, dioestrus), dominant follicles of successive waves undergo atresia (Bergfelt et al., 1991). The dominant follicle present at the onset of luteolysis becomes the ovulatory follicle, and emergence of the next wave is delayed until the day of the ensuing ovulation. The corpus luteum begins to regress earlier in two-wave cycles (day 16) than in three-wave cycles (day 19) resulting in a correspondingly shorter oestrous cycle ( 20 days versus 23 days, respectively). Hence, the mean interval of 21 days occurs only as an average between two- and three-wave cycles.

\section{FSH and the wave phenomenon}

Each follicular wave is preceded by a surge in circulating FSH; hence, cows with two-wave cycles have two FSH surges and three-wave cycles have three surges (Fig. 1; Adams et al., 1992b). This observation has been confirmed in several subsequent studies (Ginther et al., 1996a). Initial detection of follicles ( $3 \mathrm{~mm}$ ) emerging within a wave occurs during the incline in the FSH surge and continues until FSH decreases to pre-surge values after about $48-72 \mathrm{~h}$ (Ginther et al., 1996b). The decline in circulating FSH is a result of negative feedback from products of the emerging follicles (Adams et al., 1992b, 1993b; Gibbons et al., 1997) and the following nadir in FSH effectively prevents new wave emergence (Bergfelt et al., 1994). Oestradiol and inhibin suppress FSH secretion in vivo and in vitro, and are likely the most important follicular products responsible for the suppressive effects involved in the wave phenomenon; however, follicular factors mediating the effects on FSH are not yet defined clearly. 
Although it has been assumed that the primary source of such factors is the dominant follicle, recent results suggest that all follicles that are $\geq 5 \mathrm{~mm}$ in diameter in a wave help to suppress FSH secretion (Gibbons et al., 1997). Studies of follicular dynamics in pregnant cows (Ginther et al., 1996a) and prepubertal calves (Adams et al., 1994; Evans et al., 1994b) have offered a good opportunity for examining the relationships between FSH and follicular wave emergence. Observations on pregnant and prepubertal animals support the notion of a positive relationship between the magnitude of the FSH surge and the number of follicles in a wave.

\section{The selection mechanism}

The mechanism of selection of the dominant follicle is based on differential responsiveness of follicles within a wave to FSH and LH (Ginther et al, 1996b). The mechanism involves, in the first instance, the post-surge decline in FSH. The time of selection (defined as divergence in growth profiles of dominant versus subordinate follicles) coincided with the first significant decrease in FSH concentrations (Adams et al., 1992b), and selection could be delayed with exogenous FSH (Adams et al., 1993a). The second important aspect in selection of the dominant follicle is a change to LH responsiveness. The transient rise in FSH permits sufficient follicular growth so that some (not all) follicles acquire LH responsiveness. This responsiveness imbues the follicle with the ability to survive without FSH. At the time that the growth profiles of the dominant and subordinate follicles begin to diverge, about 2 days after wave emergence, the follicle destined to become dominant apparently has more LH receptors and the competitive advantage over incipient subordinate follicles. However, subordinate follicles can achieve dominance if the original dominant follicle is removed (Adams et al., 1993b; Gibbons et al., 1997) or if exogenous FSH is supplied (Adams et al,, 1993a). Furthermore, the competition for LH among multiple dominant follicles (that is, superstimulated with FSH) is apparent by the smaller maximum diameter attained compared with single dominant follicles (Adams et al., 1993a). In this regard, comparative observations in sheep (see section below) provide a rationale for the hypothesis that there is a relative difference in LH responsiveness between monovular and polyovular species such that more follicles attain the ability to use $\mathrm{LH}$ in the latter.

During the growing and static phases, continued secretion of follicular products from the dominant follicle causes FSH to be suppressed to its nadir, and together with continued suppression of $\mathrm{LH}$ as a consequence of luteal phase progesterone secretion, the dominant follicle ceases its metabolic functions and begins to die. In this way, the dominant follicle may play a role in its own demise as well as that of its subordinates. Upon cessation of follicle-product secretion, FSH is again allowed to surge. This surge has no effect on the dying dominant follicle, but stimulates emergence of the next wave. The ovarian cycle then continues. Relief from progestational suppression (that is, luteolysis) allows LH pulse frequency to increase, permitting further growth of the dominant follicle and markedly higher circulating concentrations of oestradiol, which results in the LH surge and ovulation.

\section{Ovarian asymmetry}

Asymmetry in follicular dynamics in the left and right ovaries of an individual has been the subject of much study, and has been used to elucidate local versus systemic mechanisms of control of ovarian function. Some workers have reported greater follicular activity in the right ovary in cattle and a higher incidence of right-side ovulation (approximately $60 \%$; reviewed in Pierson and Ginther, $1987 \mathrm{~b}$ ), whereas others report that there are no differences (Ginther et al., 1989b; Sirois and Fortune, 1988). Ginther (1989b) concluded that the dominant follicle effects follicle suppression by systemic rather than local channels. A positive intra-ovarian effect of the corpus luteum on the development of small antral follicles ( $\leq 3 \mathrm{~mm}$ ) has been documented in sheep (Dufour et al. 1972) and cattle (Pierson and Ginther, 1987b), but this effect did not extend to the large dominant follicles (Pierson and Ginther, 1987b; Ginther et al., 1989b). On the contrary, the corpus luteum of pregnancy has been 


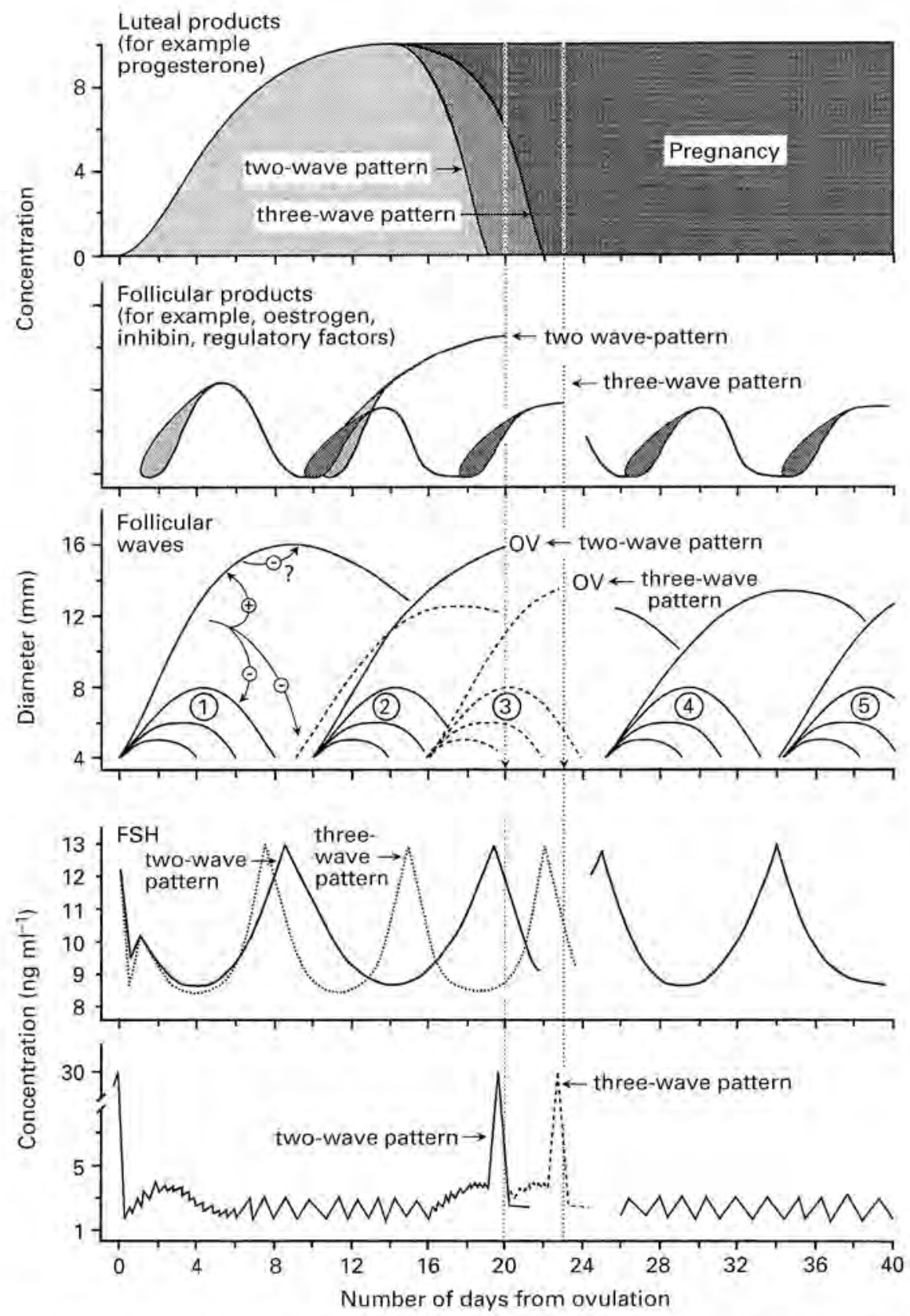

Fig. 1. Proposed model of bovine ovarian follicular wave dynamics during two-wave (-) and threewave (-) interovulatory intervals (OV, ovulation), and early pregnancy (anovulatory; for example waves 4,5$)$. Follicle diameter profiles are represented in the middle panel, luteal and follicular products are represented in the upper panels, and gonadotrophin profiles are depicted in the lower panels. Shapes drawn for follicular products represent the relative number of follicles contributing to the pool at a given time. Shapes taper as subordinate follicles of each wave regress, leaving only the dominant follicle as the main producer. Episodic pulses of LH are schematic and do not represent actual pulse frequency and amplitude. Hypotheses indicated by arrows in the middle panel are (1) the dominant follicle suppresses its subordinates and emergence of the next follicular wave, and (2) the dominant follicle contributes to self-growth and self-demise. (Modified from Adams and Pierson, 1995.) 


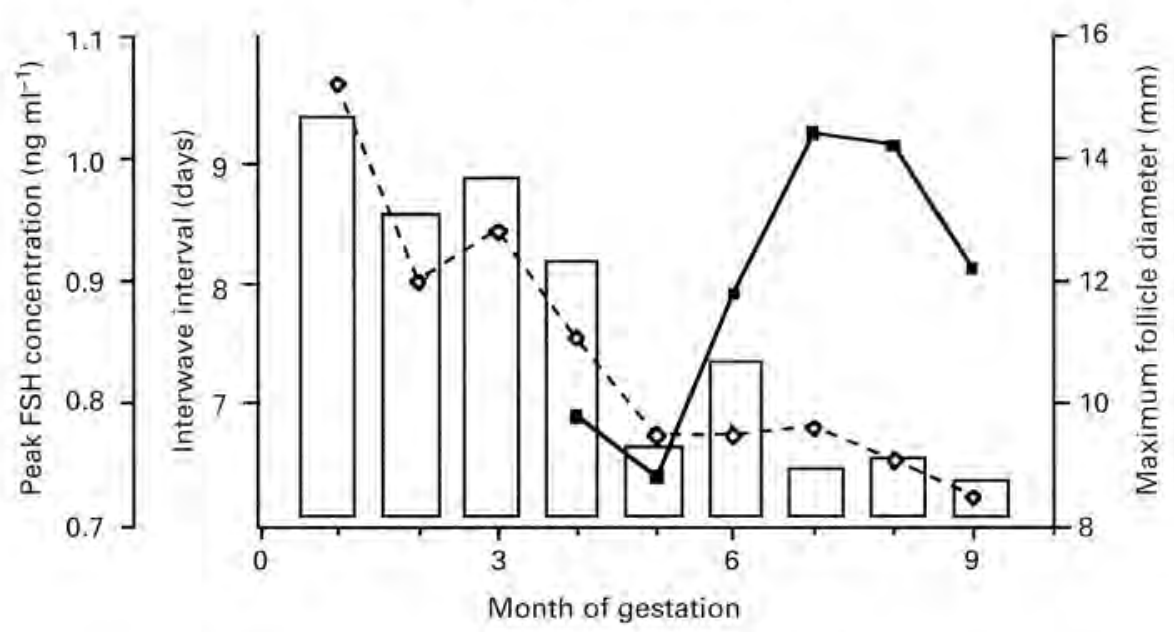

Fig. 2. Interrelationship between circulating concentrations of FSH ( $\mathbf{a})$, maximum diameter of the dominant follicle $(\diamond)$, and the interwave interval (bars) in pregnant cattle. Values are means. (Data from Bergfelt et al., 1991; Ginther et al., 1996a.)

associated with a negative intra-ovarian effect on the dominant follicle (Ginther et al, 1989b). Although the luteal-follicular relationships during the first two waves were similar in pregnant and nompregnant cows (that is, no differential effects between ovaries), dominant follicles of successive waves during pregnancy were more frequently $(75-80 \%)$ found in the ovary contralateral to the corpus luteum. The cause of the negative local association between the corpus luteum and the follicles is unknown but it may be directly related to the conceptus rather than to the corpus luteum (Bergfelt et al., 1991; Thatcher et al., 1991). These findings have important implications regarding mechanisms controlling ovarian function and the roles of locally produced ovarian peptides. It appears that the two ovaries act primarily as a single unit, and follicular counterparts between ovaries influence each other through systemic rather than local routes.

\section{Pregnancy and postpartum period}

Regular periodic emergence of anovulatory follicular waves has been detected throughout pregnancy, except for the last 21 days when follicles $\geq 6 \mathrm{~mm}$ in diameter were not detected (Bergfelt et al., 1991; Ginther et al., 1996a). In the presence of progesterone (endogenous or exogenous; Bergfelt et al., 1991), anovulatory follicular waves emerged at regular intervals. However, the maximum diameter of the dominant follicle of successive waves decreased, and was associated with a successive decrease in the interwave interval (that is, the period of dominance became shorter; Fig. 2). An initial decrease occurred immediately after the first follicular wave of pregnancy, and a subsequent sharp decrease occurred after the fourth month of pregnancy. Progesterone suppresses growth of the dominant follicle in a dose-dependent manner (Adams et al., 1992a), and the progressive decrease in follicular dominance seen in pregnant cattle was attributed to rising progesterone during mid-pregnancy, and rising oestrogen near term (Ginther et al, 1996a). The mean interval between successive FSH surges (6.8 days) and follicular waves (6.9 days) was nearly identical and, of 118 waves examined, $83 \%$ emerged within 1 day of the peak in the FSH surge. In addition to the temporal relationships, the magnitude and frequency of FSH surges were influenced by the size of the dominant follicle. Waves in which the dominant follicle reached a diameter of $\geq 10$ $\mathrm{mm}$ were associated with longer intervals between successive FSH surges and lower concentrations of FSH (Fig. 2). Conversely, waves with smaller dominant follicles (that is, $6-9 \mathrm{~mm}$ ) were associated 
Table 1. Characteristics of post-partum ovarian events in dairy and beef cattle

\begin{tabular}{llc}
\hline End point & Dairy cattle & Beef cattle \\
\hline Emergence of first follicular wave (days postpartum) & $4(2-7)$ & $\leq 10$ \\
Percentage ovulating from first postpartum wave & 74 & 11 \\
First ovulation (days postpartum) & $21(10-55)$ & 31 \\
First oestrus (days postpartum) & $59(17-139)$ & - \\
Percentage with a short interovulatory interval (s 14 days) & 25 & 78 \\
\hline
\end{tabular}

with shorter intervals and higher concentrations of FSH. A similar inter-relationship between FSH and follicular wave dynamics was demonstrated in prepubertal calves.

Recrudescence of follicular wave development occurs early in the postpartum period in both beef and dairy cattle (Table 1, Rajamahendran and Taylor, 1990; Savio et al., 1990; Ginther et al., 1996a). First ovulation was not accompanied by oestrous behaviour in 17 of $18(94 \%)$ postpartum dairy cows, and the duration of the first postpartum interovulatory interval varied depending on when the first follicle destined to ovulate emerged. Short postpartum anovulatory periods (about 14 days) were followed by cycles of normal duration (18-21 days), whereas longer postpartum anovulatory periods (21-25 days) were followed by short cycles ( $<14$ days). Short cycles were associated with shorter luteal phases, a smaller corpus luteum, and lower circulating progesterone concentrations.

There were small differences in postpartum ovarian function between dairy and beef cattle and these were differences in magnitude rather than in basic nature (Table 1). The first ovulation occurred later in beef than in dairy cattle and rarely from the dominant follicle of the first postpartum wave (Murphy et al., 1990). In the majority of beef cows $(78 \%$ ), ovulation occurred from the second, third or fourth postpartum follicular wave, and as in dairy cattle, first ovulations occurring after 20 days ( 16 of 18 cows) were followed by a short cycle ( 14 of 16 cows). Slightly earlier resumption of ovulatory cyclicity in dairy cows may be attributed to the effects of calf suckling in beef cattle, and greater selection pressure for this characteristic in dairy cattle.

\section{Prepubertal period}

Ovarian follicular dynamics in prepubertal heifers have only recently been investigated (Adams et al., 1994; Evans et al., 1994a, b). Transrectal ultrasonography was used to monitor daily changes in follicular development in calves from 2 weeks of age; calves were monitored at regular intervals during the first year of life. Puberty was defined as the time of the first ovulation, and was determined to be 52-56 weeks (12-13 months) in the Hereford-cross heifers used in the study. Follicular development occurred in a wave-like fashion, similar to that in adults, at all ages examined. Individual follicle development was characterized by growing, static and regressing phases, and periodic surges in serum concentrations of FSH were associated with follicular wave emergence (Fig. 3). FSH surges lasted for a mean of 3 days and were maximal 1 day before wave emergence.

It appears that adult-like interplay between the ovaries and the hypothalamo-pituitary axis begins to emerge at about 14 weeks of age. Periodic surges in FSH elicited periodic emergence of follicular waves, which in turn periodically suppressed FSH. The gradual increase in LH during the first year of life (mean and pulse frequency; Evans et al., 1994a) appears to be responsible for the gradual increase in dominant follicle diameter, which in turn causes a longer period of dominance and progressively longer interwave intervals. Finally, at puberty, sufficient LH is released to induce ovulation, and follicular wave development similar to that of the prepubertal period is punctuated by regular ovulation thereafter. Unlike the prepubertal period, follicular wave development in sexually mature cattle is influenced by progesterone during regular luteal phases. 

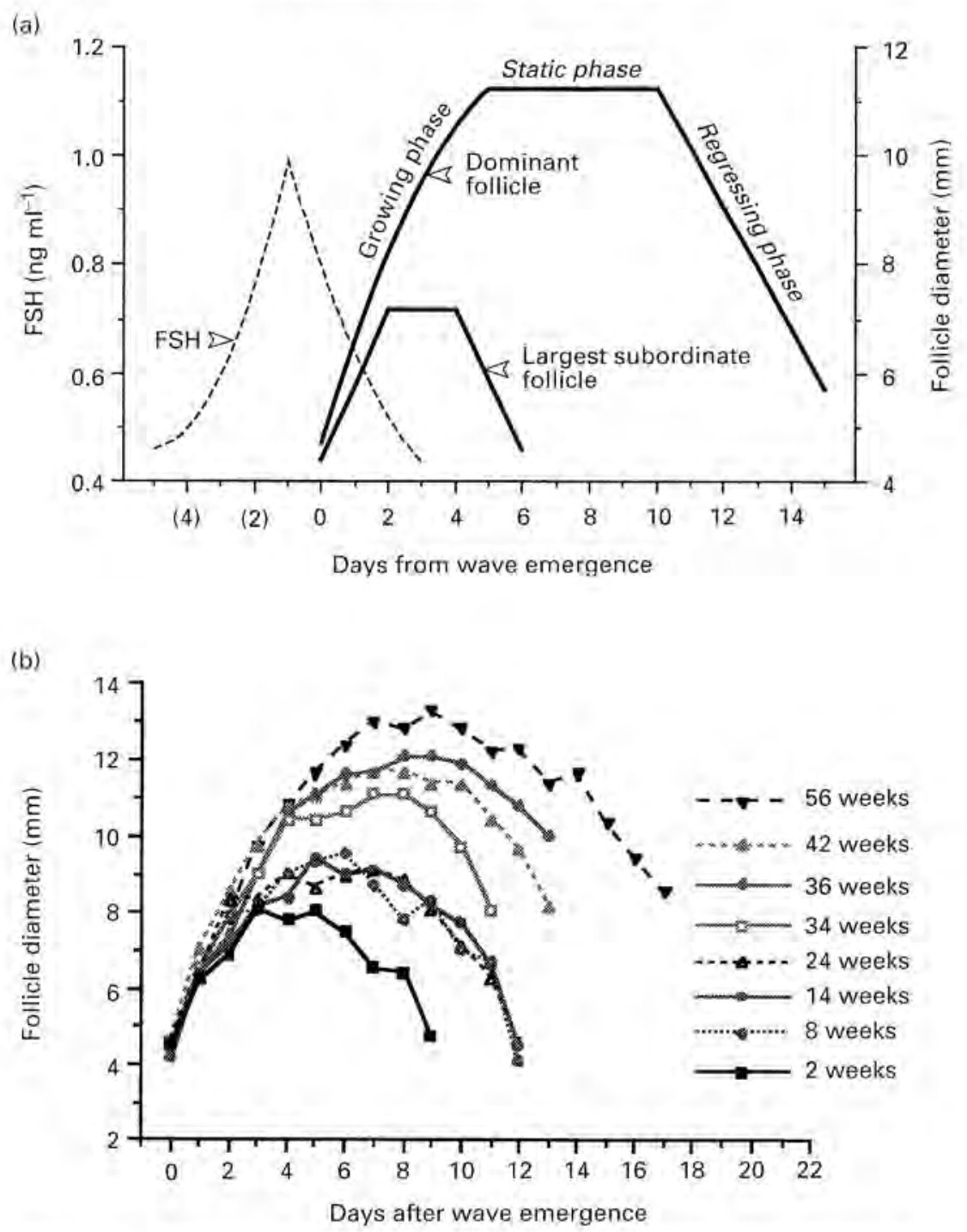

Fig. 3. (a) Temporal association between surges in circulating concentrations of FSH and emergence of anovulatory follicular waves in prepubertal heifers (regression analysis; Adams et al., 1994), and (b) increasing magnitude of mean diameter profiles of the dominant follicle of successive anovulatory follicular waves in calves between 2 and 56 weeks of age. (Data from Evans et al., 1994a,b.)

The diameter profile of the dominant as well as the largest subordinate follicle in prepubertal calves increased with age (Figs. 3 and 4). The increase was greatest from 2-8 weeks of age and again between 24 and 40 weeks of age, in temporal association with increases in mean concentrations of LH (Evans et al, 1994b). The number of follicles detected ( $23 \mathrm{~mm}$ in diameter) also increased markedly between 8 and 14 weeks of age and then decreased thereafter, in temporal association with the early rise and subsequent decrease in FSH concentrations. The early rise in circulating concentrations of LH and FSH between 4 and 14 weeks of age may reflect initial maturation of the hypothalamo-pituitary axis and subsequent sensitivity to negative feedback by ovarian steroids. 

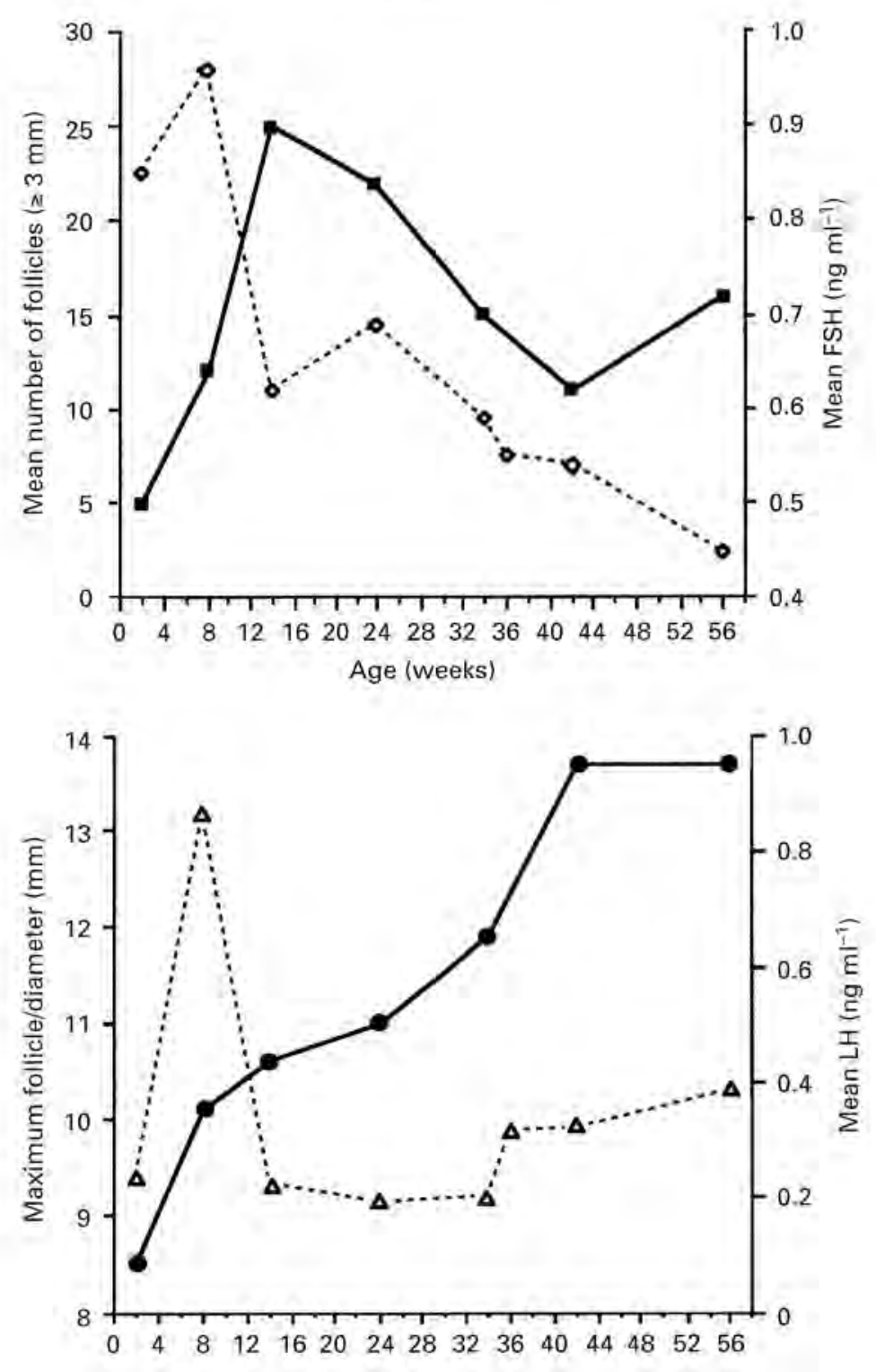

Age (weeks)

Fig. 4. Temporal association (means) between circulating concentrations of gonadotrophins $(\diamond, \mathrm{FSH} ; \triangle, \mathrm{LH})$ and ovarian follicle development ( number of follicles; $\bullet$ maximum diameter of follicles) in calves from birth to puberty. Mean onset of puberty (age at first ovulation) was 56 weeks (data from Evans et al., 1994a,b).

This notion is supported by data illustrated in Fig. 4, and in observed changes in the interval between the emergence of dominant follicles of successive waves (interwave interval). The interwave interval was relatively long ( $8-9$ days) at 2 and 8 weeks of age, but was significantly shorter ( 6.8 days) at 14 weeks. The interwave interval gradually increased ( $7-9$ days) thereafter until puberty. 
At the onset of puberty, the first ovulatory cycle was short $(7.7 \pm 0.2$ days) and the first ovulation occurred after the dominant follicle had entered the static phase: that is, the dominant follicle was older at the time of ovulation than its counterpart of later cycles. The first corpus luteum (from the aged ovulatory follicle) was smaller and shorter-lived than corpora lutea of subsequent cycles, thus resulting in a short interovulatory interval. The second interovulatory interval was of normal duration $(20,3 \pm 0.5$ days $)$ and was composed of two $(n=3)$ or three $(n=7)$ follicular waves. These results demonstrate a striking similarity between the onset of puberty in young heifers and recrudescence of ovulatory cyclicity in postpartum cows.

\section{Other Ruminant Species}

\section{Sheep and goats}

For over three decades understanding of the pattern of ovarian follicular development in sheep has been clouded by a lack of consensus among reports. Follicular growth has been described as continuous and independent of the stage of the oestrous cycle (Hutchinson and Robertson, 1966; Yenikoye et al., 1989; Schrick et al., 1993; Lopez-Sebastian et al., 1997). Conversely, results from a number of studies involving serial hormone (oestradiol and FSH) measurement, histomorphology, repeated laparoscopy and daily ultrasonography support the notion that follicular growth is wavelike in sheep (reviewed in Noel et al., 1993; Ravindra et al., 1994; Ginther et al., 1995; Bartelewski et al., 1998a,b). Similar controversy has surrounded folliculogenesis in goats (Ginther and Kot, 1994) and the confusion is not unlike that experienced with respect to follicular dynamics in cattle during the 1980s (Adams and Pierson, 1995). Apart from inconsistencies in the number of follicular waves reported, temporal relationships between follicular and endocrine data from recent studies provide compelling support for the concept that follicular growth in sheep and goats occurs in a wave-like pattern.

In an initial study involving daily transrectal ultrasonography of Western White Face ewes (Rambouillet $\times$ Columbia), the emergence of follicles from a pool of follicles $\leq 2 \mathrm{~mm}$ in diameter was detected on most days of the oestrous cycle, but there was a significant increase on days 2 and 11 (day $0=$ ovulation; Ravindra et al., 1994). Similarly, in another study involving serial ultrasonography of Polypay ewes (Ginther et al., 1995), an organized pattern of development was not detected in follicles that reached only 3 or $4 \mathrm{~mm}$, but follicles that grew to $\geq 5 \mathrm{~mm}$ in diameter emerged at regular intervals during the oestrous cycle, leading authors to conclude that the majority of oestrous cycles consisted of four or more follicular waves (Table 2). There was a tendency for FSH to increase in concentration 2-3 days before wave emergence and there was a close correlation between the number of waves and the number of FSH peaks during the oestrous cycle $(4.1 \pm 0.3$ and $4.5 \pm 0.3$, respectively) and between the duration of the interwave interval and the interval between FSH peaks ( $4.0 \pm 0.3$ days and $3.6 \pm 0.2$ days, respectively).

Most recent ultrasound studies (Bartelewski et al., 1998b) confirm a distinct wave-like pattern of follicle development during the oestrous cycle in both non-prolific (Western White Face) and prolific (Finn) breeds of sheep (Table 2). No differences between breeds were found in the pattern of follicular development except that in the Finn sheep, the diameter of the dominant follicle was slightly smaller $(5.6 \pm 0.2 \mathrm{~mm}$ versus $6.7 \pm 0.2 \mathrm{~mm}$ ), FSH concentrations were higher around the day of ovulation, the dominant follicle from the penultimate wave of the cycle often ovulated along with that of the ultimate wave, and the ovulation rate was greater $(2.7 \pm 0.2$ versus $1.8 \pm 0.2)$. Consistent with the previous study, the number of follicular waves and the number of FSH peaks per cycle did not differ $(3.7 \pm 0.2$ and $3.8 \pm 0.1$ ), and the interwave interval was highly correlated with the interpeak interval in FSH. In addition, the number of peaks in circulating oestradiol concentration did not differ from the number of follicular waves per cycle $(3.5 \pm 0.2$ and $3.8 \pm 0.1)$, and the interwave interval was highly correlated with the interval between oestradiol peaks. Similar findings have been reported for goats (Ginther and Kot, 1994): the predominant pattern (75\%) consisted of four follicular waves emerging at intervals of 3-4 days during a 23 day oestrous cycle 
Table 2. Comparative aspects of ovarian follicular waves during the oestrous cycle among domestic and wild ruminants

\begin{tabular}{|c|c|c|c|c|c|c|c|}
\hline \multirow[b]{2}{*}{ Species } & \multirow{2}{*}{$\begin{array}{l}\text { Number of } \\
\text { waves/cycle } \\
\text { (\% of cycles) }\end{array}$} & \multirow{2}{*}{$\begin{array}{l}\text { IWI } \\
\text { (days) }\end{array}$} & \multirow{2}{*}{$\begin{array}{c}\text { IOI } \\
\text { (days) }\end{array}$} & \multicolumn{4}{|c|}{ Maximum follicle diameter (mm) } \\
\hline & & & & Wave $1^{a}$ & Wave 2 & Wave 3 & Wave 4 \\
\hline \multirow[t]{2}{*}{ Cattle } & \multirow{2}{*}{$\frac{2}{3}(>95 \%)^{4}$} & 10 & 20 & 15 & 15 & - & - \\
\hline & & 8 & 23 & 15 & 12 & 15 & - \\
\hline \multirow[t]{3}{*}{ Sheep } & $3(8-29 \%)$ & & $9-16$ & \multirow{3}{*}{$5-7$} & \multirow{3}{*}{$4-6$} & \multirow{3}{*}{$4-6$} & \multirow{3}{*}{$5-7$} \\
\hline & $4(60-80 \%)$ & $3.5-4.5$ & $16-17$ & & & & \\
\hline & $>4(0-34 \%)$ & & $22-24$ & & & & \\
\hline Goat & 4 & $3-4$ & 23 & 9 & 7 & 7 & 10 \\
\hline \multirow[t]{2}{*}{ Musk oxen } & \multirow[t]{2}{*}{$3-4$} & \multirow[t]{2}{*}{5} & \multirow[t]{2}{*}{23} & \multirow[t]{2}{*}{10} & \multirow[t]{2}{*}{7} & 6 (minor) & \multirow[t]{2}{*}{10} \\
\hline & & & & & & 10 (major) & \\
\hline
\end{tabular}

$\mathrm{IWI}=$ interwave interval; $\mathrm{IOI}=$ interovulatory interval.

'In all species, the first follicular wave emerges on the day of ovulation \pm 1 day.

${ }^{b}$ Some report a majority $(>80 \%)$ of either 2 waves or 3 waves.

Table 3. Characteristics of ovarian follicular waves in musk oxen $(n=4)$ during an annual cycle

\begin{tabular}{lccc}
\hline Characteristic & $\begin{array}{c}\text { Anovulatory } \\
\text { season }\end{array}$ & Transition $^{\text {t }}$ & $\begin{array}{c}\text { Ovulatory } \\
\text { season }^{\text {b }}\end{array}$ \\
\hline $\begin{array}{l}\text { Interovulatory interval (days) } \\
\text { Number of waves per cycle }\end{array}$ & - & $6.5 \pm 0.5$ & $22.8 \pm 1.1$ \\
Interwave interval (days) & $6.3 \pm 0.3$ & 1 & $3-4$ \\
Maximum follicle diameter $(\mathrm{mm})$ & $9.5 \pm 0.3$ & $10.5 \pm 0.7$ & $5.4 \pm 0.2$ \\
\hline
\end{tabular}

"The first interovilatory interval of the ovulatory season.

the second interovulatory interval of the ovulatory season.

(Table 2). Few changes were noted in the characteristics of follicular waves from the beginning to the end of the anovulatory season in ewes (March-July; Bartelewski et al., 1998a). Periodic fluctuations in FSH were associated with regular wave emergence, and circulating $\mathrm{LH}$ concentrations were suppressed throughout the anovulatory season. No differences were detected in maximum follicle diameter, interwave interval or circulating concentrations of FSH during successive follicular waves of the anovulatory period. The number of $2-4 \mathrm{~mm}$ follicles increased transiently early in the anovulatory period (Ravindra and Rawlings, 1997; Bartelewski et al., 1998a).

A confounding aspect of studying follicular dynamics in sheep and goats is the apparent difference in the nature or magnitude of follicle dominance compared with that of cattle. In sheep, the wave pattern has been detected only in follicles destined to grow to $\geq 5 \mathrm{~mm}$ in diameter; consequently, very few follicles (that is, one to three per wave) are detectable for characterizing the wave pattern, complete with follicle selection and dominance. Indeed, there is controversy about whether follicular dominance exists in sheep (Driancourt et al., 1991; Lopez-Sebastian et al., 1997), and if it does, it is certainly less distinct than in cattle. However, the following observations support the notion of dominance in sheep, particularly during the first and last waves of the cycle: (1) emergence of follicular waves associated with a follicle larger than all others was detected during metoestrus and pro-oestrus in sheep (Ravindra et al., 1994; Ginther et al., 1995; Bartelewski et al., $1998 \mathrm{~b}$ ) and goats (Ginther and Kot, 1994), (2) following prostaglandin-induced luteolysis on various days of the oestrous cycle, the proportion of ewes that ovulated the largest follicle at the time of 


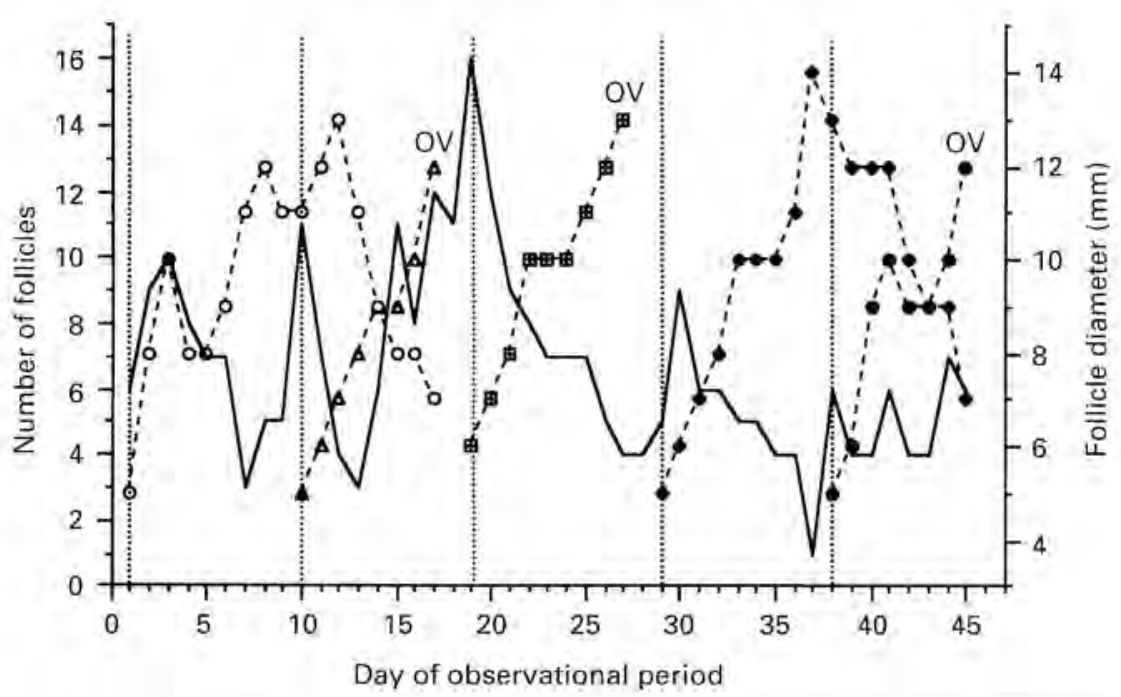

Fig. 5. Changes in the number of follicles $\geq 4 \mathrm{~mm}$ (-) relative to the diameter of successive dominant follicles (-...) in a Wapiti hind during transition from the anovulatory period to the first 2 ovulatory cycles of the season (September to November). Vertical dotted lines indicate wave emergence. OV, ovulation (R. B. McCorkell and G. P. Adams, unpublished).

treatment and the interval to oestrus varied relative to the day of treatment (Houghton et al., 1995), and (3) follicular and ovulatory responses to superstimulatory gonadotrophin treatment were influenced by the status of the follicular wave at the time of treatment, and the presence of a large growing follicle at the time treatment was initiated was associated with lower follicle recruitment, fewer ovulations, and fewer embryos (Rubianes et al., 1997). These observations are consistent with those made in cattle in which variation in the ovulatory response to prostaglandin treatment and ovarian superstimulation have been attributed directly to the status of follicular dominance at the time treatment was initiated (reviewed in Adams, 1994).

Follicular waves in sheep and goats, as in horses (Ginther, 1993), may be better characterized as major waves, with a clearly discernible dominant follicle (occurring at the beginning and end of the oestrous cycle), and minor waves, with no clear dominant follicle (occurring during dioestrus). Results of independent studies suggest that the dominant follicle of waves emerging early or late in the oestrous cycle grow to a larger diameter (Table 2) and are associated with a longer lifespan than that of mid-cycle waves (Ravindra et al., 1994; Ginther and Kot, 1994; Ginther et al., 1995; Bartelewski et al., 1998b). The suppressive effects of progesterone on the growth of the dominant follicle have been clearly documented (Adams et al., 1992a; Johnson et al., 1996) and provide a rationale for the hypothesis that the absence of dominance in minor waves is a result of progesterone-induced suppression of LH during dioestrus, whereas the presence of dominance in major waves is a result of a relative lack of progesterone suppression during metoestrus and pro-oestrus.

\section{Musk oxen}

In the first detailed study of ovarian follicular dynamics in a wild species, daily transrectal ultrasonography was conducted on a group of four captive musk oxen. Follicular waves were apparent during both the ovulatory (Hoare et al, 1997) and anovulatory seasons (S. Parker and G. P. Adams, unpublished; Tables 2 and 3). Only one wave was detected during the first (short) cycle of the ovulatory season. During the second (long) cycle of the ovulatory season, one musk ox had three waves and the remaining three animals had four waves. Only the dominant follicle of the last wave 
of the oestrous cycle ovulated; the dominant follicle of other waves regressed slowly over a period of a few days. Dominance was manifested in the first and last follicular waves of the oestrous cycle in each of the four animals (major waves), whereas the other waves in all but one instance appeared to be minor waves. Wave characteristics and indistinct follicular dominance during dioestrus are remarkably similar to that observed in sheep and goats (cited above), species to which the musk ox is most closely related. Insight of this kind is important in the design of appropriate artificial breeding systems and, in this respect, the musk ox may provide a useful model for the endangered takin (Budorcas taxicolor). A detailed knowledge of ovarian events may also be critical to the interpretation of the response of wild populations to environmental stress.

\section{Cervids}

A paucity of information is available on ovarian function in deer. Two recent papers demonstrate different approaches to the study of follicular development, and the approaches have led to different conclusions. In one study (McLeod et al., 1996), ovaries excised from hinds on different days after oestrous synchronization were dissected to determine the number and size of follicles, and to distinguish between healthy versus atretic follicles. A wide variation among hinds was observed in the total number of follicles present on a given day and in the percentage of follicles that were healthy. Results led the authors to conclude that there was a lack of an obvious pattern of follicle development and that a large oestrogenic follicle was present in all animals at all stages of the oestrous cycle. The second study (Asher et al., 1997) involved transvaginal ultrasonographic monitoring of surgically modified hinds to study follicular changes on a daily basis. The ovaries were sutured to the peritoneal surface of the vaginal fornix to permit consistent access during daily examinations. Results were equivocal in that they observed a highly variable and generally nonsynchronous pattern of growth and regression of the largest follicle, but emergence of new follicles $3 \mathrm{~mm}$ in diameter was more pronounced on days 1 and 14 of the oestrous cycle. These authors also stated that most oestrous cycles were associated with either two or three consecutive large follicles and that the emergence of one or two new follicles $\geq 3 \mathrm{~mm}$ in diameter occurred only during the early growth phase of the presumptive preovulatory follicle or after the demise of the preceding large follicle. In the only other study of follicular dynamics in cervids that the author is aware of, the ovaries of ten Wapiti (North American elk) were examined daily by transrectal ultrasonography during the transition from the anovulatory to the ovulatory seasons (September-November* $\mathrm{R}$. B. McCorkell and G. P. Adams, unpublished). Preliminary inspection of data suggests a distinct wavelike pattern during the first (short; 10.7 days) and second (long, 19.0 days) oestrous cycles of the ovulatory season (Fig. 5).

\section{Camelids}

Unlike other ruminant species, camelids (llama, alpaca, guanaco, vicuna, and dromedary and bactrian camels) are induced or reflex ovulators. Hence, camelids possess three naturally occurring reproductive statuses which may be expected to influence follicular and luteal dynamics: (1) the unstimulated anovulatory condition, (2) ovulatory but nonpregnant (for example, non-fertile mating), and (3) ovulatory and pregnant. An initial ultrasound study of the effects of lactational and reproductive status on patterns of follicle growth and regression (Adams et al., 1990) documented a distinct wave-like pattern of follicular development in llamas. Llamas were examined daily by transrectal ultrasonography for $\geq 30$ days and results demonstrated that follicular activity occurred in waves for all reproductive statuses and that lactation and the presence of a corpus luteum were associated with depressed follicular development. Waves of follicular activity were indicated by periodic increases in the number of follicles detected and an associated emergence of a dominant follicle that grew to $\geq 7 \mathrm{~mm}$. The dominant follicle of a wave was first identified at a diameter of $3-4$ $\mathrm{mm}$, and subordinate follicles did not exceed $7 \mathrm{~mm}$ in diameter. The emergence of the first anovulatory dominant follicle was detected, on average, 3 days after ovulation in females mated to a 


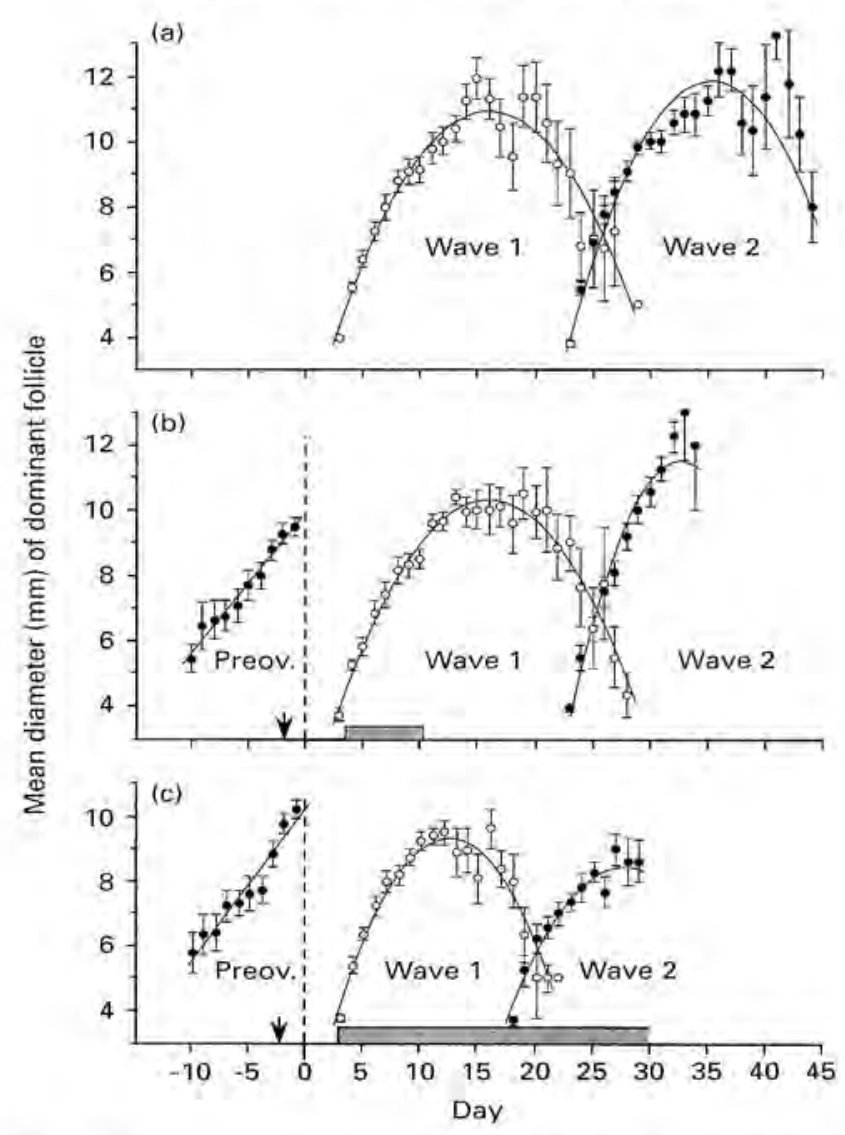

Fig. 6. Diameter profiles (mean \pm SEM) of the dominant follicle in (a) anovulatory llamas (non-mated), (b) ovulatory non-pregnant llamas (mated to vasectomized males), and (c) ovulatory pregnant llamas (mated to intact males). Arrows indicate mean day of mating (ovulation $=$ day 0 ) and shaded bars indicate the days of detection of the corpus luteum for the ovulatory groups (Adams et al., 1990). Preov.; preovulatory.

vasectomized or intact male. The interwave interval was $19.8 \pm 0.7$ days in unmated and vasectomy-mated llamas and $14.8 \pm 0.6$ days in pregnant llamas (Fig. 6). Lactation was associated with an interwave interval that was shortened, on average, by $2.5 \pm 0.5$ days. Maximum diameter of anovulatory dominant follicles ranged from 9 to $16 \mathrm{~mm}$ and was greater for non-pregnant llamas than for pregnant llamas (anovulatory group, $12.1 \pm 0.4 \mathrm{~mm}$; ovulatory non-pregnant group, $11.5 \pm 0.2 \mathrm{~mm}$; pregnant group, $9.7 \pm 0.2 \mathrm{~mm}$ ). In addition, lactation was associated with a smaller maximum diameter of dominant follicles averaged over all reproductive statuses $(10.4 \pm 0.2$ versus $11.7 \pm 0.3 \mathrm{~mm}$ ). The presence (ovulatory non-pregnant group) and persistence (pregnant group) of a corpus luteum was associated with a depression in the number of follicles detected and a smaller diameter profile of dominant follicles (Fig. 6).

Reports in alpacas using a laparoscopic technique (cited in Bravo et al., 1990), and in llamas using transrectal palpation or ultrasonography (Bravo et al., 1990), are consistent with the presence of a wave-like pattern of follicular growth in camelids. However, notable differences in the character of follicular growth were found between the studies. The interval between emergence of successive follicles was not stated, but examination of follicular profiles from individual alpacas shows an 
approximate interwave interval of 15 days. Similar results were obtained in the llama study; the apparent dominant follicle spanned approximately 14 days and the apparent mean interwave interval was 11.1 days. In studies with both alpaca and llama, the dominant follicle of successive waves alternated regularly between left and right ovaries in over $80 \%$ of the intervals. In contrast, results of others (Adams et al., 1990) indicated that the growth and regression profile of the dominant anovulatory follicle of each wave lasted 20-25 days and the interwave interval was 20 days for nonpregnant llamas. Moreover, the incidence of alternation of successive dominant follicles between left and right ovaries did not differ from the incidence of non-alternation. The differences between studies seem too great to reconcile, but lactational status may have contributed to some of the disparity in results. However, the issue has become more confusing by a recent report in which the interwave interval for postpartum llamas was only 8 days (Bravo et al., 1995).

The wave-like pattern of follicular development has also been documented in dromedary camels (Skidmore et al., 1995), and wave characteristics are similar to those of llamas. As in llamas, distinct follicular dominance was manifest by a strong inverse relationship between the number of follicles detected and the diameter of the largest follicle. The interwave interval for unmated camels was 18.2 days.

\section{Conclusion}

The procesś of follicular development permits some (one in monovular species) follicles to continue to grow and have the potential to ovulate (appropriately a competitive process with much physiological reserve or excess), while at the same time minimizes attrition from the reserve pool by suppressing recruitment between waves. Periodic follicular suppression of FSH preserves the resources of the ovary by preventing continuous recruitment of large antral follicles, $99 \%$ of which are lost to atresia. To date, the wave pattern of follicular development has been demonstrated in every species in which it has been examined including cattle, sheep, goats, horses, camelids, and some wild ungulates. Concepts emerging from results of recent studies of ovarian function in these species are consistent with mechanisms implied in the bovine model (Fig. 1). Differences in follicular dynamics between ruminant species appear to be more in detail rather than in essence. Data from many studies involving serial hormone measurement, gross and histological examination of excised ovaries, repeated laparoscopy, and daily ultrasonography support the notion that (1) follicles grow in a wave-like fashion; (2) periodic surges in circulating FSH are associated with follicular wave emergence; (3) selection of a dominant follicle involves a decline in FSH and acquisition of LH responsiveness; (4) periodic anovulatory follicular waves continue to emerge until occurrence of an LH surge (that is, at the time of luteolysis during the ovulatory season or during transition from the anovulatory season); (5) within species, there is a positive relationship between the duration of the oestrous cycle and the number of follicular waves; (6) progesterone is suppressive to LH secretion and to the growth of the dominant follicle; (7) the duration of the interwave interval is a function of follicular dominance, and is negatively correlated with circulating FSH; (8) follicular dominance in all species is more pronounced during the first and last follicular waves of the oestrous cycle; and (9) pregnancy, the prepubertal period, and seasonal anoestrus are characterized by regular, periodic surges in FSH and emergence of anovulatory follicular waves.

\section{References}

Adams GP (1994) Control of ovarian follicular wave dynamics in cattle: implication for synchronization and superstimulation Theriogenology 41 25-30

Adams GP and Pierson RA (1995) Bovine model for study of ovarian follicular dynamics in humans Theriogénology 43 $113-120$

Adams GP, Sumar J and Ginther OJ (1990) Effects of lactational status and reproductive status on ovarian follicular waves in llamas (Lama glama) Journal of Reproduction and Fertility 90 535-545

Adams GP, Matteri RL and Ginther OJ (1992a) The effect of progesterone on growth of ovarian follicles, emergence of follicular waves and circulating FSH in heifers foumal of Reproduction and Fertility $95627-640$ 
Adams GP, Matteri RL, Kastelic JP, Ko JCH and Ginther OJ (1992b) Association between surges of follicle stimulating hormone and the emergence of follicular waves in heifers Journal of Reproduction and Fertility 94 177-188

Adams GP, Kot K, Smith CA and Ginther OJ (1993a) Selection of a dominant follicle and suppression of follicular growth in heifers Animal Reproduction Science 30 259-271

Adams GP, Kot K, Smith CA and Ginther OJ (1993b) Effect of the dominant follicle on regression of its subordinates in heifers Canadian Journal of Animal Science 73 267-275

Adams GP, Evans ACO and Rawlings NC (1994) Follicular waves and circulating gonadotrophins in 8-month-old prepubertal heifers Journal of Reproduction and Fertility 100 27-33

Ahmad N, Townsend EC, Dailey RA and Inskeep EK (1997) Relationship of hormonal patterns and fertility to occurrence of two or three waves of ovarian follicles, before and after breeding, in beef cows and heifers Animal Reproduction Science 4913-28

Asher GW, Scott IC, O'Neill KT, Smith IF, Inskeep EK and Townsen EC (1997) Ultrasonographic monitoring of antral follicle development in red deer (Cerous elaphus) Journal of Reproduction and Fertility 111 91-99

Bartelewski PM, Beard AP, Cook SJ and Rawlings NC (1998a) Ovarian follicular dynamics during anoestrus in ewes Journal of Reproduction and Fertility 113 275-285

Bartelewski PM, Beard AP, Cook SJ, Chandolia RK, Honoramooz A and Rawlings NC (1998b) Ovarian antral follicular dynamics and their relationships with endocrine variables throughout the oestrous cycle in breeds of sheep differing in prolificacy Journal of Reproduction and Fertility 115 111-124

Bergfelt DR, Kastelic JP and Ginther OJ (1991) Continued periodic emergence of follicular waves in nonbred progesterone-treated heifers Animal Reproduction Science 24 193-204

Bergfelt DR, Plata-Madrid H and Ginther OJ (1994) Counteraction of the follicular fluid inhibitory effect of follicular fluid by administration of FSH in heifers Canadian Journal of Animal Science 74 633-639

Bravo PW, Fowler ME, Stabenfeldt GH and Lasley BL (1990) Ovarian follicular dynamics in the llama Biology of Reproduction 43 579-585

Bravo PW, Lasley BL and Fowler ME (1995) Resumption of ovarian follicular activity and uterine involution in the postpartum llama Theriogenology 44 783-791

Driancourt MA, Webb R and Fry RC (1991) Does follicular dominance occur in ewes? journal of Reproduction and Ferfility $9363-70$

Dufour J, Ginther OJ and Casida LE (1972) Intraovarian relationship between corpora lutea and ovarian follicles in ewes American Journal of Veterinary Research 33 1445-1446

Evans ACO, Adams GP and Rawlings NC (1994a) Endocrine and ovarian follicular changes leading up to the first ovulation in prepubertal heifers Journal of Reproduction and Fertility $100187-194$

Evans ACO, Adams GP and Rawlings NC (1994b) Follicular and hormonal development in prepubertal heifers from 2 to 36 weeks of age Journal of Reproduction and Fertility $102463-470$

Gibbons JR, Wiltbank MC and Ginther OJ (1997) Functional interrelationships between follicles greater than $4 \mathrm{~mm}$ and the follicle-stimulating hormone surge in heifers Biology of Reproduction 57 1066-1073

Ginther OJ (1993) Major and minor follicular waves during the equine estrous cycle Journal of Equine Veterinary Science 13 $18-25$
Ginther OJ and Kot K (1994) Follicular dynamics during the ovulatory season in goats Theriogenology 42 987-1001

Ginther OJ, Knopf L and Kastelic JP (1989a) Temporal associations among ovarian events in cattle during oestrous cycles with two and three follicular waves Jourrial of Reproduction and Fertility 87 223-230

Ginther OJ, Kastelic JP and Knopf L (1989b) Intraovarian relationships among dominant and subordinate follicles and the corpus luteum in heifers Theriogenology $32787-795$

Ginther OJ, Kot K and Wiltbank MC (1995) Associations between emergence of follicular waves and fluctuations in FSH concentrations during the estrous cycle in ewes Theriogenology $43689-703$

Ginther OJ, Kot K, Kulick LJ, Martin S and Wiltbank MC (1996a) Relationships between FSH and ovarian follicular waves during the last six months of pregnancy in cattle Journal of Reproduction and Fertility 108 271-279

Ginther OJ, Wiltbank MC, Fricke PM, Gibbons JR and Kot K (1996b) Selection of the dominant follicle in cattle Biology of Reproduction 55 1187-1194

Hoare EK, Parker SE, Flood PF and Adams GP (1997) Ultrasonic imaging of reproductive events in muskoxen Rangifer 17 $119-123$

Houghton JAS, Liberati N, Schrick FN, Townsend EC, Dailey RA and Inskeep EK (1995) Day of estrous cycle affects follicular dynamics after induced luteolysis in ewes fournal of Animal Science 73 2094-2101

Hutchinson JSM and Robertson HA (1966) The growth of the follicle and corpus luteum in the ovary of the sheep Research in Veterinary Science 7 17-24

Johnson SK, Dailey RA, Inskeep EK and Lewis PE (1996) Effect of peripheral concentrations of progesterone on follicular growth and fertility in ewes Domestic Animal Endocrinology 13 $69-79$

Lopez-Sebastian A, Gonzalez de Bulnes A, Santiago Moreno J, Gomez-Brunet A, Townsend EC and Inskeep EK (1997) Patterns of follicular deyelopment during the estrous cycle in monovular Merino del Pais ewes Animal Reproduction Science 48 279-291

McLeod BJ, Meikle LM, Heath DA, McNatty KP, Fisher MW and Whaanga AJ (1996) Ovarian follicle development in the red deer hind New Zealand Society of Animal Production 56 $370-372$

Murphy MG, Boland MP and Roche JF (1990) Pattern of follicular growth and resumption of ovarian activity in post-partum beef suckler cows Journal of Reproduction and Fertility 90 523-533

Murphy MG, Enright WJ, Crowe MA, McConnell K, Spicer LJ, Boland MP and Roche JF (1991) Effect of dietary intake on pattern of growth of dominant follicles during the estrous cycle in beef heifers Journal of Reproduction and Fertility 92 333-338

Noel B, Bister JL and Paquay R (1993) Ovarian follicular dynamics in Suffolk ewes at different periods of the year Journal of Reproduction and Fertility 99 695-700

Pierson RA and Ginther OJ (1987a) Follicular populations during the estrous cycle in heifers: I. Influence of day Animal Reproduction Science 14 165-176

Pierson RA and Ginther OJ (1987b) Follicle populations during oestrous cycle in heifers: II. Influence of right and left sides and intraovarian effect of the corpus luteum Animal Reproduction Science 14 177-186

Rajamahendran R and Taylor C (1990) Characterization of ovarian activity in postpartum dairy cows using 
ultrasound imaging and progesterone profiles Animal Reproduction Science 22 171-180

Ravindra JP and Rawlings NC (1997) Ovarian follicular dynamics in ewes during the transition from anoestrus to the breeding season Journal of Reproduction and Fertility 110 279-289

Ravindra JP, Rawlings NC, Evans ACO and Adams GP (1994) Ultrasonographic study of ovarian follicular dynamics in ewes during the oestrous cycle Joumal of Reproduction and Fertility 101 501-509

Rhodes JM, De'ath G and Entwistle KW (1995) Animal and temporal effects on ovarian follicular dynamics in Brahman heifers Animal Reproduction Science 38 265-277

Roche JF and Boland MP (1991) Turnover of dominant follicles in cattle of different reproductive states Theriogenology 35 $81-90$

Rubianes E, Ungerfeld R, Vinoles C, Rivero A and Adams GP (1997) Ovarian response to gonadotrophin treatment initiated relative to wave emergence in ultrasonogxaphically monitored ewes Theriogenology 47 1479-1488

Savio JD, Keenan L, Boland MP and Roche JF (1988) Pattern of growth of dominant follicles during the oestrous cycle of heifers Journal of Reproduction and Fertility 83 663-671

Savio JD, Boland MP, Hynes N and Roche JF (1990) Resumption of follicular activity in the early postpartum period of dairy cows Journal of Reproduction and Fertility 88 569-579

Schrick FN, Surface RA, Pritchard JY, Dailey RA, Townsend EC and Inskeep EK (1993) Ovarian structures during the estrous cycle and early pregnancy in ewes Biology of Reproduction $491133-1140$

Sirois J and Fortune JE (1988) Ovarian follicular dynamics during the estrous cycle in heifers monitored by real-time ultrasonography Biology of Reproduction 39 308-317

Skidmore JA, Billah M and Allen WR (1995) The ovarian follicular wave pattern in the mated and non-mated dromedary camel (Camelus dromedarius) Journal of Reproduction and Fertility 49 545-548

Thatcher WW, Driancourt MA, Terqui M and Badinga L (1991) Dynamics of ovarian follicular development in cattle following hysterectomy and during early pregnancy Domestic Animal Endocrinology 8 223-234

Yenikoye A, Mariana JC and Celeux G (1989) Follicular growth during the oestrous cycle in Peul sheep Animal Reproduction Science 21 201-211

Zeitoun MM, Rodriguez HF and Randel RD (1996) Effect of season on ovarian follicular dynamics in Brahman cows Theriogenology 45 1577-1581 